\title{
Is Brand Name Best? Brand Name Versus Generic Pharmaceuticals in Clinical Practice
}

\author{
Andrea Bakker, BSc, Pharmacology and Therapeutics ${ }^{1}$
}

${ }^{1}$ Faculty of Medicine, Univeristy of Ottawa

\section{A BSTRACT}

In the last few years some of the biggest 'blockbuster drugs', that is the drugs that make pharmaceutical companies billions of dollars, have lost their patents. This means that generic manufacturers are able to produce these medications at a fraction of the cost. But what really differentiates generics from brand name medications? This commentary will explore how differences in licensing affect drug efficacy and how the pharmaceutical landscape in Canada affects patient care.

\section{RÉ S U MÉ}

Au cours des dernières années, les brevets de certains des plus grands " médicaments vedettes ", c'est-à-dire des médicaments qui rapportent des milliards de dollars aux compagnies pharmaceutiques, sont arrivés à échéance. Cela signifie que les fabricants de médicaments génériques peuvent désormais produire ceux-ci à moindre coût. Mais qu'est-ce qui différencie véritablement les médicaments génériques de ceux d'origine? Ce commentaire examinera comment les différences en ce qui a trait aux licences affectent l'efficacité des médicaments, et comment le panorama pharmaceutique au Canada affecte les soins de santé.

\section{INTRODUCTION}

It's a common scenario: standing in front of the cereal isle debating between 'Cheerios' and the less-than-appealing 'Toasted Oat' generic version. Sure, Cheerios is the original and has that ever persuasive bee on the box, but the generic is superior in terms of cost. Of course, the generic tastes about the same, but depending on the store, the generic version is slightly differentnothing compares to the consistency of a bowl of tried and true Cheerios. A similar decision is made by physicians when deciding between brand name medications and generics. Since 2010, several 'blockbuster drugs', which are drugs that make pharmaceutical companies billions of dollars, have lost their patents [1]. This phenomenon is commonly referred to as the 'patent cliff' [1]. As another 'patent cliff' is set to occur from 2014 to 2020 [1], we will see generic manufacturers take over the production of brand name medications at a fraction of the cost. For example, 2015 saw Abilify, a popular antipsychotic, and Lantus, a long-acting insulin, lose their patents [1]. What does this mean for patients? Are brand name drugs clinically superior? How are generic and brand name drugs licenced and what does this mean in terms of their efficacy and potency? This commentary will highlight the differences between brand name and generic drugs that prescribers may want to consider before putting pen to prescription pad.

The pharmaceutical landscape in Canada underwent a drastic change when, in 1969, legislation allowed Canada to import generic drugs [2]. This resulted in a large influx of generic pharmaceuticals into the Canadian market and was followed by ad- ditional reform that mandated generic substitution for brand name drugs unless explicitly specified by the physician [2]. Today, due to automatic substitution laws in Ontario, even if a physician prescribes Lipitor, the patient will receive generic Atorvastatin [3]. The physician can try to specify that the brand name drug is preferred by writing "Lipitor, no subs" [3], however the increased cost of the brand name may not be covered by insurance programs. For example, patients on the Ontario Drug Benefit program will be required to try two interchangeable generic products and have a documented Adverse Drug Reaction (ADR) to both before being eligible to receive the brand name medication at no additional charge [4]. In addition to receiving the generic version, automatic substitution states that the patient is to receive the least expensive generic brand of Atorvastatin with which the pharmacy is currently stocked [3]. In order to understand how automatic generic substitutions might affect patient care, we must first understand how the two types of drugs are produced and licensed.

\section{DRUG DEVELOPMENT}

In terms of drug development (Table 1), brand name pharmaceutical companies are responsible for the research and development (R\&D) of their new medications, including arranging preclinical and clinical trials [5]. This process usually takes over ten years and has an estimated cost of $\$ 2.6$ billion per drug [6]. Many drugs do not pass these trials. For every 5,000 to 10,000 chemicals that enter preclinical testing, only one makes it onto the market [7]. If drug trials are successful, the pharmaceutical company is warranted a 20-year patent which begins early in drug 
Table 1: Drug development differences between brand name and generic pharmaceuticals

\begin{tabular}{|l|l|l|}
\hline \multicolumn{2}{|l|}{ Process } & Brand Name \\
\hline $\begin{array}{l}\text { Research and } \\
\text { Development }\end{array}$ & Performs [5] & Does not perform [5] \\
\hline Trials & $\begin{array}{l}\text { Preclinical [5] } \\
\text { Clinical Trials } \\
\text { (Phases I, II, III) [5] }\end{array}$ & $\begin{array}{l}\text { Pharmaceutical } \\
\text { equivalence [7] } \\
\text { Bioequivalence [7] }\end{array}$ \\
\hline $\begin{array}{l}\text { Cost for } \\
\text { Development }\end{array}$ & $>10$ years & $\begin{array}{l}\text { 2-3 years } \\
\text { \$2.6 billion USD [6] million USD [5] }\end{array}$ \\
\hline Patent & 20 years & None \\
\hline
\end{tabular}

development, thus only affording the company about ten years of protected time on the market [8]. Conversely, generic pharmaceutical companies do not develop new drugs [5]. Instead, once brand name drug patents expire, the generic pharmaceutical company submits an application for drug manufacturing. The generic company is only required to prove pharmaceutical equivalence and bioequivalence to the brand name drug [7]. This process only takes two to three years and costs $\$ 3-10$ million [5].

\section{DIFFERENCES IN DRUG PRODUCT}

In terms of differences in the product itself (Table 2), brand name drugs contain the original combination of the active ingredient and binders that was tested in clinical trials [9]. Brand name drugs often cost at least $50 \%$ more than generic [9] but have the advantage of maintaining consistent packaging and therefore are more recognizable to physicians and patients. Generics, however, have the same active molecule but are bound by different excipients and packaged differently [9]. They are more likely to be covered by insurance and are the default medications used in hospital. Unfortunately, the type of generic used, whether it be from Teva Pharmaceuticals or Apotex Pharmaceuticals for example, is subject to change depending what the pharmacy is using to stock their shelves [10]. Importantly, a patient may be taking warfarin from Teva Pharmaceuticals for several years, but if their pharmacy changes their supplier to Apotex, the patient may now be receiving Apotex warfarin which will look different and may have a different potency. This occurs unbeknownst to the prescribing physician. The potential implications of this occult change will be expanded upon in this commentary.

With all of these differences in mind, there are a few key distinguishing factors that physicians must consider before prescribing medications. These include differences in efficacy and packaging
Table 2: Differences in the drug product between brand name and generic

\begin{tabular}{|l|l|l|}
\multicolumn{3}{|c|}{ Brand Name } \\
\hline Components & $\begin{array}{l}\text { Active Compo- } \\
\text { nent }\end{array}$ & $\begin{array}{l}\text { Same active molecule } \\
\text { Different excipients and } \\
\text { packaging [9] }\end{array}$ \\
\hline Cost & $\begin{array}{l}50 \% \text { higher than } \\
\text { generic [9] }\end{array}$ & \\
\hline Coverage & & $\begin{array}{l}\text { Covered by insurance, } \\
\text { used in hospital }\end{array}$ \\
\hline Packaging & Consistent & $\begin{array}{l}\text { Changes depending on } \\
\text { generic in stock }\end{array}$ \\
\hline $\begin{array}{l}\text { Target } \\
\text { Audience }\end{array}$ & $\begin{array}{l}\text { Physicians, } \\
\text { Patients }\end{array}$ & Pharmacies \\
\hline
\end{tabular}

between generic and brand name pharmaceuticals.

\section{DIFFERENCES IN DRUG EFFICACY}

Differences in efficacy arise from the process in which generic drugs are approved. Generics must demonstrate pharmaceutical equivalence and bioequivalence to brand name drugs [7]. Pharmaceutical equivalents are pharmaceuticals that contain the same active ingredient in the same dosage, form, and route of administration as the brand name drug [11]. Bioequivalence is a pharmacokinetic equivalence and is demonstrated through a single-dose, two-treatment, crossover-designed study in normal adult volunteers [11]. In this study, the area under the curve (AUC), which represents drug absorption over time, and maximum drug concentration (Cmax) are measured [11]. These two values must have a $90 \%$ confidence interval $(\mathrm{Cl})$ that is between $80-125 \%$ of the brand name drug [11] (Figure 1). For example, if one were to look at the AUC for a generic drug, it could be only $90 \%$ of the brand name, however, as long as the $\mathrm{Cl}$ falls between $80 \%$ and $125 \%$ of the brand name AUC, this drug would be approved. If it had a small $\mathrm{Cl}$, this would mean that patients taking the drug are usually receiving only $90 \%$ of what is expected. In addition, when pharmacies switch between different brands of generic medications, a process which often occurs unbeknownst to the physician, this could result in going from a generic delivering $90 \%$ of the expected drug to one delivering $110 \%$. Theoretically, this could be a problem with drugs that have a narrow therapeutic index or a critical dose [11].

\section{CLINICAL OUTCOMES WITH GENERIC VERSUS BRAND NAME MEDICATIONS}

Several studies have attempted to address the theoretical difference in efficacy between generic and brand name medications. 


\section{Commentary}

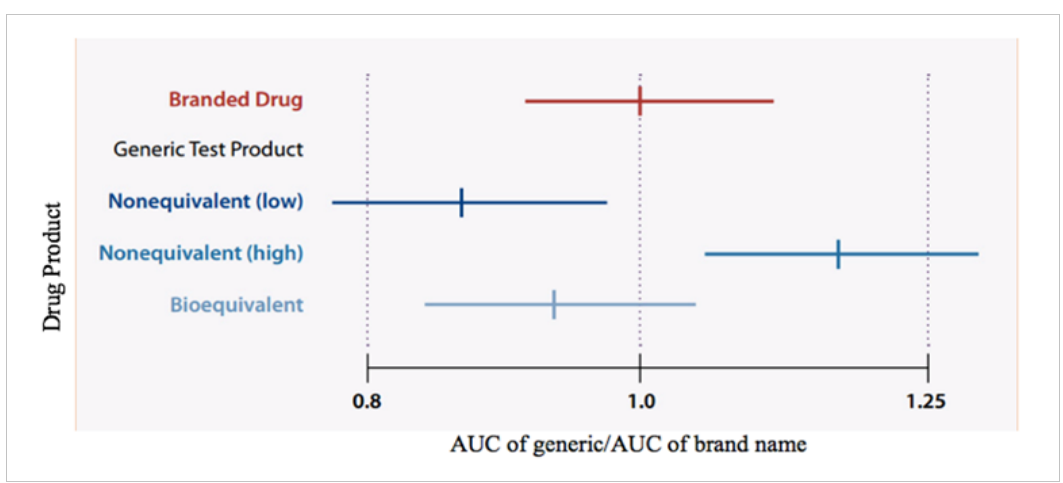

Figure 1: Possible results for testing generic drugs. The Area Under the Curve (AUC) of the generic drug is compared to the brand name. Two examples of drugs are shown that have $90 \%$ confidence intervals $(\mathrm{Cl})$ extending beyond the acceptable range. The bottom example falls within the viable range and would be accepted despite the fact that its AUC value is below the target value [13].

A recent case-control study of about 78,000 patients found no difference between generic and brand name antihypertensives in terms of hospitalization for cardiovascular disease [12]. This is in line with the fact that minor variations in blood pressure are unlikely to have a clinically noticeable impact on long-term outcomes. What about medications with a narrow therapeutic index? A recent review of 40,000 patients on warfarin demonstrated no statistically significant difference in international normalized ratio (INR) or dose adjustments after switching to generic drugs and no increase in adverse effects [14]. Nonetheless, on an individual level, the study found up to a $10 \%$ change in INR values after switching to generic [14]. Similarly, a recent meta-analysis of antiepileptic medications found no difference in the rates of uncontrolled seizures between generic and brand name phenytoin, carbamazepine, and valproic acid [15]. The researchers noted an increase in hospitalization when medication was changed from one generic brand to another ( $H R=1.6(1.1-2.5))$ but not for changing from brand name to generic [15]. This is in line with the concept that there could be more variability between different types of generic medications than between brand name and a given type of generic.

\section{CONCERTA: A CASE-STUDY IN PHARMACOKINETICS}

Recently, concerns arose with regards to the generic versions of Concerta. Concerta, also known as methylphenidate, is a Central Nervous System (CNS) stimulant used for treatment of attention deficit hyperactivity disorder (ADHD). Anecdotal reports stated that certain generic versions of the medication were not effective [16]. There are currently three generic versions of Concerta being used in North America. Only Concerta and the Actavis generic formulation use a time-release technology called osmotic controlled-release oral delivery system (OROS), which is a special system that ensures slow release of the medication over 10 to 12 hours [16]. The other two generic versions do not use the OROS system [16]. A recent study provided objective evidence that the
non-OROS generics provided inferior treatment of ADHD symptoms compared to OROS formulations mostly due to inadequate duration of action [16]. In light of the approval process discussed above, this makes sense. Both formulations have the same dose of the same active molecule. They will both result in similar amounts of drug absorbed (AUC) and similar maximal concentrations (Cmax), meaning that non-OROS drugs would be approved under the current standards. Nonetheless, the time at which the maximal dose is reached differs between the non-OROS and OROS formulations which results in an inferior clinical outcome with non-OROS generics.

\section{APPEARANCE OF MEDICATIONS IS IMPORTANT FOR PATIENT COMPLIANCE}

Another important difference between generic and brand name drugs is appearance. Only weeks into my clinical rotations, I soon learned that patients rarely remember the names of their medications. They do, however, remember medication appearance. It is common knowledge in the medical field that 'the blue puffer' is salbutamol, but pragmatic patients only remember that they should take the blue puffer if they cannot breathe. Imagine the problems that would arise if salbutamol was changed to a red puffer.

A recent case control study in the Annals of Internal Medicine confirmed this. It analyzed patients post-myocardial infarction taking cardiac medications [17]. The study identified patients who discontinued medication and recorded if there was a recent change in pill shape or colour [17]. The study found that the odds of non-persistence increased $34 \%$ and $66 \%$ after a change in pill colour and pill shape, respectively [17]. The researchers attributed the discontinuation to patient skepticism and mistrust of the pharmacy when pill appearance was changed [17]. This is important because the packaging of brand name drugs is consistent, whereas the packaging of generics is not only different but can 


\section{Commentary}

change if the pharmacy changes their generic supplier. This can result in patient non-compliance.

\section{CONCLUSION}

In conclusion, as we approach another 'patent cliff', I suggest thinking of generic and brand name drugs in a similar way to how one shops at the grocery store. Generally, generics are less expensive and have comparable efficacy, but have the disadvantage of having packaging that is inconsistent between generic brands. They work well, but switching to a generic from a brand name and switching between generics is the hardest part. When selecting medications, it is important to consider the differences in medication licensing and the implications that it may have on your patient. A higher degree of vigilance is paramount for medications in which pharmacokinetics are crucial, because these generic medications may pass the approval process but still possess key differences that could affect patient outcomes. Finally, remember that despite what is written on the prescription, patients receive generic medications by default. The brand of generic depends on the pharmacy and can change regularly, resulting in patient confusion. So, is brand name best? Well like most things in medicine, the answer is: it depends.

\section{REFERENCES}

1. Kakkar AK. Patent cliff mitigation strategies: Giving new life to blockbusters. Expert Opin Ther Pat. 2015;25(12):1353-9.

2. Sanders JC. Limited lists of drugs: Lessons from abroad. Br Med J (Clin Res Ed). 1985;290(6469):710.

3. Anis AH. Pharmaceutical policies in Canada: another example of federalprovincial discord. CMAJ. 2000;162(4):523-6.

4. Regulation Amendments in support of Sustainability and Access for the Ontario Drug Benefit Program [Internet]. Ministry of Health and LongTerm Care; 2015 Sep 17 [cited 2016 Jan 30] Available from: http://www. health.gov.on.ca/en/pro/programs/drugs/opdp_eo/notices/fq_exec_office_20150917_1.pdf

5. Pharmaceutical Industry Profile [Internet]. Industry Canada; 2015 Jan 19 [cited 2015 Nov 2]. Available from: https://www.ic.gc.ca/eic/site/lsg-pdsv. nsf/eng/h_hn01703.html.

6. Cost to Develop and Win Marketing Approval for a New Drug Is \$2.6 Billion [Internet]. Tufts Centre for the Study of Drug Development; 2014 Nov 14 [cited 2015 Nov 2] Available from: http://csdd.tufts.edu/news/complete_ story/pr_tufts_csdd_2014_cost_study.

7. Klees JE, Joines R. Occupational health issues in the pharmaceutical research and development process. Occup Med. 1997;12(1):5-27.

8. Heilman RD. Drug development history, "overview," and what are GCPs? Qual Assur. 1995;4(1):75-9.

9. Chawla K, Tofighi T, Agarwal A, Thomas J, Mondal T. A Global Comparison Between Brand-Name and Generic Drugs. Indian Journal of Pharmacy Practice. $2014 ; 7(3): 23-8$

10. Hollis A. The importance of being first: evidence from Canadian generic pharmaceuticals. Health Econ. 2002;11(8):723-34.

11. Kefalas $\mathrm{CH}$, Ciociola AA. The FDA's generic-drug approval process: similarities to and differences from brand-name drugs. Am J Gastroenterol. 2011;106(6):1018-21.

12. Corrao G, Soranna D, Merlino L, Mancia G. Similarity between generic and brand-name antihypertensive drugs for primary prevention of cardiovascular disease: Evidence from a large population-based study. Eur J Clin Invest. 2014;44(10) 933-9.

13. Fraser T, Tilyard M. BPJ, special edition: generics [Internet]. Dunedin, New Zealand: bpacnz Ltd; 2009 Jul. [cited 2016 Jan 1]. Available from: http:// www.pharmac.govt.nz/2009/08/25/bpjse_generics_2009.pdf.

14. Dentali F, Donadini MP, Clark N, et al. Brand name versus generic warfarin: A systematic review of the literature. Pharmacotherapy. 2011;31(4):386-93.

15. Kesselheim AS, Stedman MR, Bubrick EJ, et al. Seizure outcomes following the use of generic versus brand-name an epileptic drugs: A systematic review and meta-analysis. Drugs. 2010;70(5):605-21.

16. Lally MD, Kral MC, Boan AD. Not All Generic Concerta Is Created Equal: Comparison of OROS Versus Non-OROS for the Treatment of ADHD. Clin Pediatr (Phila). 2016;55(13):1197-201.

17. Kesselheim AS, Bykov K, Avorn J, Tong A, Doherty M, Choudhry NK. Burden of changes in pill appearance for patients receiving generic cardiovascular medications after myocardial infarction: Cohort and nested case-control studies. Ann Intern Med. 2014;161(2) 96-103. 